\title{
Impact of Extreme Precipitation Intensity on Tea Production in the North-East of Bangladesh
}

\author{
Murad Ahmed Farukh* (D), Md. Atiqur Rahman, Sraboni Sarker, Md. Azharul Islam \\ Department of Environmental Science, Bangladesh Agricultural University, Mymensingh, Bangladesh \\ Email: *farukh_envsc@bau.edu.bd
}

How to cite this paper: Farukh, M. A., Rahman, Md. A., Sarker, S., \& Islam, Md. A. (2020). Impact of Extreme Precipitation Intensity on Tea Production in the NorthEast of Bangladesh. American Journal of Climate Change, 9, 441-453.

https://doi.org/10.4236/ajcc.2020.94028

Received: August 31, 2020

Accepted: December 19, 2020

Published: December 22, 2020

Copyright $\odot 2020$ by author(s) and Scientific Research Publishing Inc. This work is licensed under the Creative Commons Attribution International License (CC BY 4.0).

http://creativecommons.org/licenses/by/4.0/

\begin{abstract}
Bangladesh is a flood prone country where precipitation amount is irregular but sometimes extreme. Among the climatic parameters, precipitation is assumed as one of the vital indicators of ongoing climate change scenarios and is equally important for tea production. In this study, 7 and 9 tea estates of Sylhet and Sreemangal were selected to analyze tea production in relation to extreme precipitation intensity. Precipitation patterns namely $90^{\text {th }}, 95^{\text {th }}$ and $99^{\text {th }}$ percentile were analyzed to find out the contribution of extreme precipitation and tea production. To attain the objectives, 3 hourly, daily, monthly, and total precipitation data from 1971 to 2014 were collected from Bangladesh Meteorological Department and Bangladesh Agricultural Development Board. Tea production data were collected from Bangladesh Tea Board, Sylhet. To find out extreme level of precipitation $90^{\text {th }}, 95^{\text {th }}, 99^{\text {th }}$ percentile precipitation days were identified and analyzed. The analyses show that 1974, 1976, 1977, 1993, 1988, 1990, 2000, 2001, 2002, and 2004 were extreme precipitation years. The average precipitation of Sylhet was higher in 2000 than in 1992 and 2014. In Sreemangal, extreme precipitation was higher in 2014 than in 1992 and 2000. For both the regions, tea production was higher in 2000 and lower in 1992 and 2014. The result shows that more extreme precipitation was responsible for higher amount of tea production. The results suggest that extreme precipitation intensity was one of the responsible factors for higher amount of tea production in Sylhet and Sreemangal.
\end{abstract}

\section{Keywords}

Extreme Precipitation, Tea Production, Percentile

\section{Introduction}

Bangladesh is a developing country where tea cultivation has advanced concurrently with the northeast Indian tea during early part of $19^{\text {th }}$ century. Tea grows 
in Bangladesh mainly in three fairly divergent ecological zones, namely Surma valley in greater Sylhet, Halda valley in Chittagong and Karatoa valley in Panchagarh district (Mamun, 2011). At present Bangladesh has 160 tea estates in different regions especially in Sylhet and Chittagong (BTB, 2015). Tea production in Bangladesh maintained an upward trend with an annual increasing rate of $1.03 \%$ with an annual production rate of 57.75 million $\mathrm{Kg}$ from 2002 to 2011 (Ahammed, 2012). There are 35 countries of the world that contributed 4162 million $\mathrm{Kg}$ of tea where Bangladesh ranked the $10^{\text {th }}$ highest producer producing 60.04 million Kg in 2010. In 2014, Bangladesh produces 63.86 million $\mathrm{Kg}$ tea and significantly contributing to the development of agriculture and export sectors (Ahammed, 2012).

Precipitation plays an important role in the agro-economy of Bangladesh. Its climate is characterized by large variations in seasonal precipitation with moderately warm temperatures and high humidity where the precipitation depends on season and location. The average annual precipitation in Bangladesh varies from $1500 \mathrm{~mm}$ in the west-central part to over $3000 \mathrm{~mm}$ in the north-east (Sylhet region) and the south-east. Rana et al. (2007) studied that about $80 \%$ of the annual precipitation over Bangladesh occurs during the southwest monsoon. The remaining 20\% precipitation occurs during pre-monsoon and post-monsoon periods. In winter (November-February), the precipitation record is the lowest and it accounts for only less than $4 \%$ of the annual total precipitation. From March to May, precipitation accounts for $10 \%-25 \%$ of the total annual precipitation. The average precipitation in this season varies from $200 \mathrm{~mm}$ in the west-central part of the country to $800 \mathrm{~mm}$ in the north-east (Cottam, 1997). The amount of precipitation during this season varies from $1000 \mathrm{~mm}$ in the west-central part to over $2000 \mathrm{~mm}$ in the south to northeast. Higher precipitation in the north-east is generally caused by the additional uplifting effect of the Meghalaya plateau. Excessive precipitation generally occurs in Bangladesh during the month of May to September (Ali, 1999). In Sylhet region, the average precipitation is $4180 \mathrm{~mm}$ while, at the foot of the abrupt Meghalaya plateau, namely at Sunamganj it is $5330 \mathrm{~mm}$ and at Lalakhal $6400 \mathrm{~mm}$, the highest in Bangladesh (Huq et al., 1998).

There are several research works regarding tea production in Bangladesh. The relationship between tea yield and weather has been discussed by Carr and Stephens (1992). Hamjah (2014) tried to find out the climatic effects on cotton and tea production. The impact of seasonal monsoon on tea leaf production has been reported by Anon (1996) and Hicks (2001). Ahmed and Mamun (2012) worked on seasonal pest in the tea cultivation. Rahman et al. (2012) worked on tea land chemical composition. Khan et al. (2012) showed the suitability of different hill land in tea production while the effect of rainfall on tea leaf production was investigated by Ali et al. (2014). Ahmed and Mamun (2012) focused on different tea cultivation system in Bangladesh. Wijeratne et al. (2007) reported that the pattern, distribution and frequency of monsoonal rainfall in Bangladesh greatly affect the quality of tea as well as quantity of yield. Boehm et al. (2016) also re- 
ported that increased rainfall affects the tea yield. Paul et al. (2014) revealed the use of bio-pesticide for the development of tea production. Tea generally exhibits a positive correlation between rainfall and its production depending on suitable rainfall patterns (Ochieng et al., 2016) but different opinions have been reported also (Wijeratne et al., 2007; Esham \& Garforth, 2013; Duncan et al., 2016). But noteworthy works on extreme or severe precipitation and tea production are very scarce for Bangladesh, and possess a demand to go through under ongoing climate change conditions especially in terms of the development of tea production. Therefore, this study was undertaken with the objectives to reveal the extreme precipitation pattern, and to find out the contribution of extreme precipitation on tea production in Sylhet region.

\section{Methodology}

\subsection{Study Areas}

Sylhet and Sreemangal were considered as the study areas for this research where 16 tea estates are located. Apart from this Sylhet and Sreemangal has separate Bangladesh Meteorological Department's (BMD) weather station. Therefore, it was comparatively easier to collect the data of long term precipitation and tea production to accomplish the research objectives. The total land area of Sylhet is $11,849.10 \mathrm{~km}^{2}$ where 20 tea estates comprise total tea production area of $5316.14 \mathrm{~km}^{2}$. Total tea production in Sylhet was 5,235,658 Kg in 2014 where the yield.ha ${ }^{-1}$ was $1102 \mathrm{Kg}$. Sylhet also possesses $821.01 \mathrm{~km}^{2}$ additional land suitable for tea cultivation. There are 7904 laborers working in these estates where the number of men worker are 3232, women 3637 and adolescent 1035 (BTB, 2015). Sreemangal is an upazilla of Moulvibazar district and known as the tea capital of Bangladesh where for miles around tea gardens are visible on the hill slopes. The total area of Moulvibazar is $64,082.11 \mathrm{~km}^{2}$ where total area of tea production is $33,681 \mathrm{~km}^{2}$. In 2014, 92 tea estates of Moulvibazar produced 36,835,519 $\mathrm{Kg}$ tea where the yield $\cdot \mathrm{ha}^{-1}$ was $1252 \mathrm{Kg}$. Moulvibazar district also has $3336.70 \mathrm{~km}^{2}$ additional lands suitable for tea cultivation. The total number of garden worker accounts 57,064 where 27,004 are men, 27,806 women and 2254 are adolescents (BTB, 2015).

The tea estates were selected based on the closeness to the meteorological stations. It was needed to maintain a secure distance to the meteorological station to find out better relation of tea production and precipitation. In Sylhet region, the estates selected for the study were Habibnagar, Burijan, Khadim, Lackatoorrah, Star, Malnicherah and Alibahar (Figure 1). All the estates are within $2 \mathrm{~km}^{2}$ from Sylhet meteorological station. In Moulvibazar district the selected tea estates were Baraoora, Zareen, BTRI Ex-Farm, M. R. Khan, Nandarani, Junglebari, Julekhanagar, Hossainabad and Sathgaon. These estates were also within $2 \mathrm{~km}^{2}$ of the Sreemangal meteorological station.

\subsection{Climatic Conditions of the Study Areas}

The climate of Sylhet is humid-subtropical with a predominantly hot and humid 
summer and experiences a relatively cool winter. The city belongs to the monsoon climatic zone, with the annual average highest temperature of $23^{\circ} \mathrm{C}(\mathrm{Au}-$ gust-October) and the average lowest temperature of $7{ }^{\circ} \mathrm{C}$ (January). Nearly $80 \%$ of the annual average precipitation of $3800 \mathrm{~mm}$ occurs between May and September. The long-term precipitation trend for Sylhet and Sreemangal districts are shown in Figure 2. The maximum and minimum temperature in Sreemangal varies from $33.2^{\circ} \mathrm{C}$ to $13.6^{\circ} \mathrm{C}$, and the annual average precipitation is 2223 $\mathrm{mm}$. Tea garden, dense bamboo and cane bushes, high flood plain, extreme precipitation and the flashy rivers are the main features here that mainly contributed by the hills of this region.

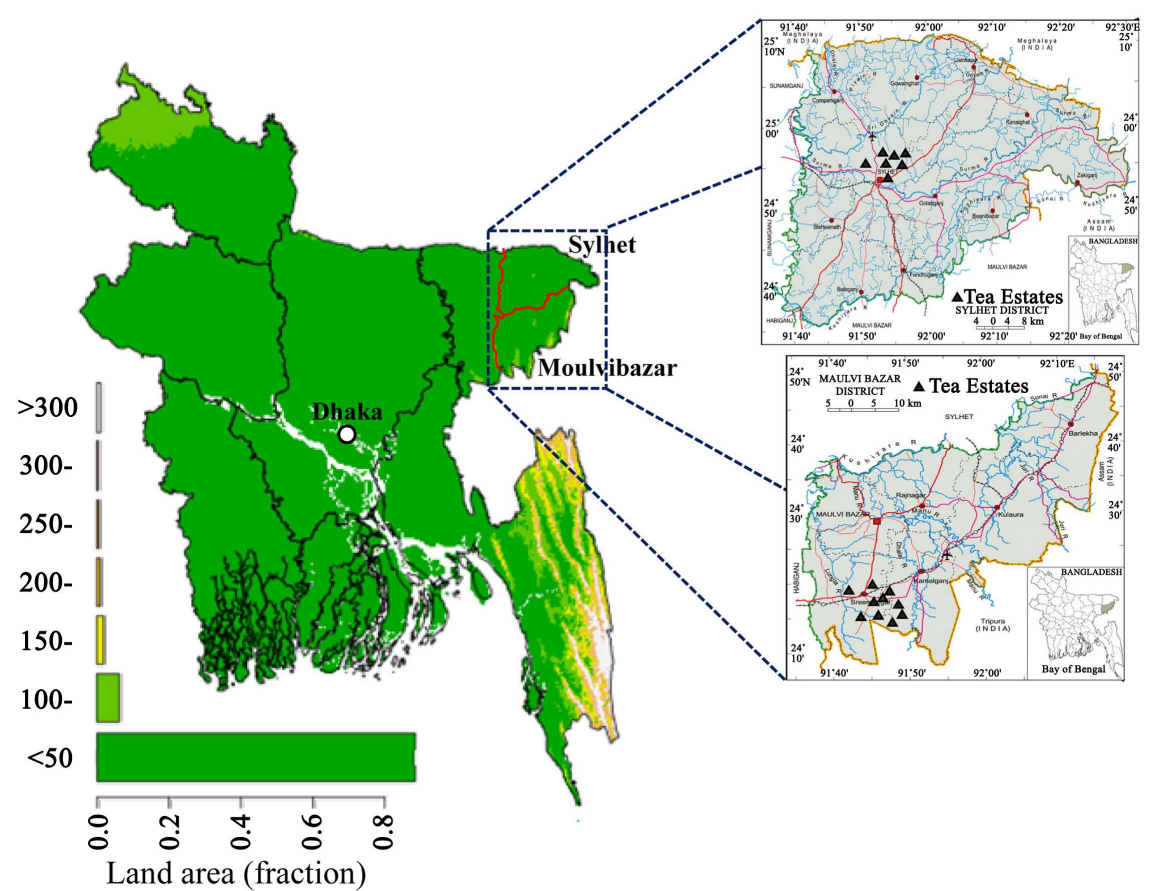

Figure 1. Selected tea estates located in Sylhet and Sreemangal districts map.

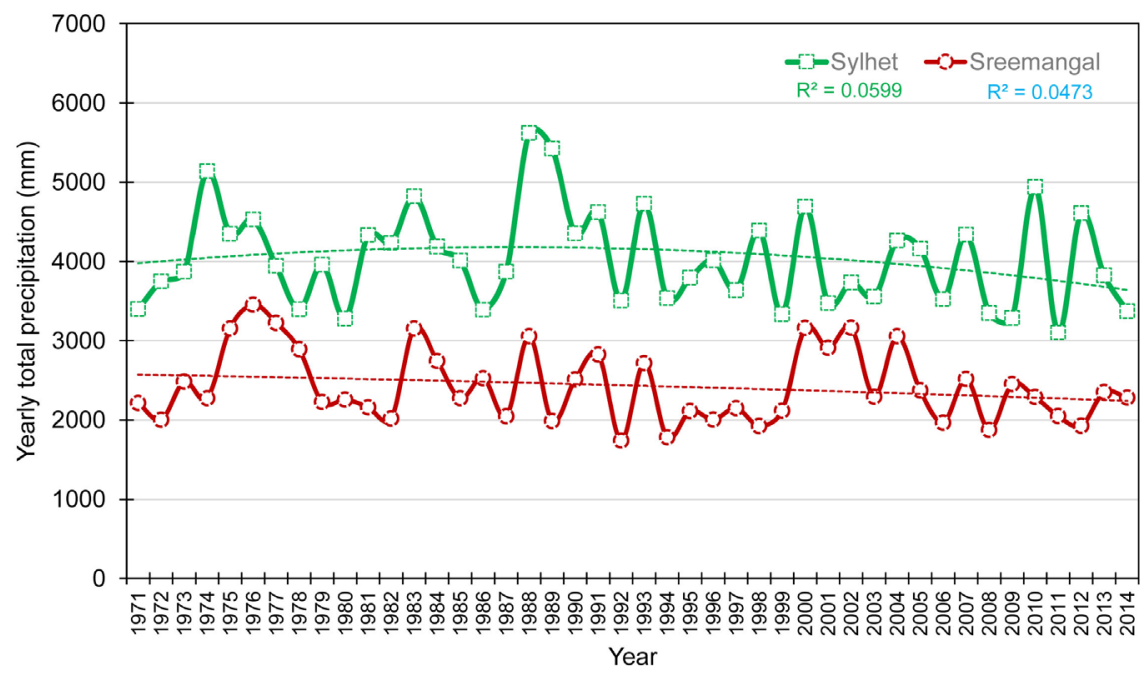

Figure 2. Time series of precipitation for Sylhet and Sreemangal districts (1971-2014). 


\subsection{Data Collection and Processing}

Long term precipitation data namely 3 hourly, daily, monthly and yearly data were collected for the period of 43 years (1971-2014) from Bangladesh Meteorological Department (BMD), Agargaon, Dhaka. Some data of precipitation were also collected from Bangladesh Agricultural Development Board (BADC), and Bangladesh Agricultural Research Council (BARC). All tea production data were collected from Bangladesh Tea Board (BTB), Sylhet, Bangladesh. The whole data were put into MS Excel spreadsheet for analyses. Data averages, standard deviations, percentiles and $\mathrm{n}^{\text {th }}$ percentile values were calculated using statistical software SPSS.

\section{Results and Discussion}

\subsection{Precipitation in Bangladesh}

Precipitation variability in space and time is one of the most relevant and dominant characteristics of the climate of Bangladesh. The generalized maps of average rainfall (in $\mathrm{mm}$ ) and average temperature $\left(\right.$ in ${ }^{\circ} \mathrm{C}$ ) are shown in Figure 3(a) and Figure 3(b), respectively to depict the baseline climate scenarios in Bangladesh. Both the figures have been derived using 1948-2016 Bangladesh Agricultural Research Council (BARC) weather station data under BARC/UNDP/FAO GIS Project (BGD/95/006). More than 75\% precipitation in Bangladesh occurs in monsoon. During the early part of the pre-monsoon, a narrow zone of air mass discontinuity lies across the country that extends from the south-west to the north-east. This discontinuity lies between the hot dry air coming from the upper Gangetic plain and the warm moist air coming from the Bay of Bengal (BB).

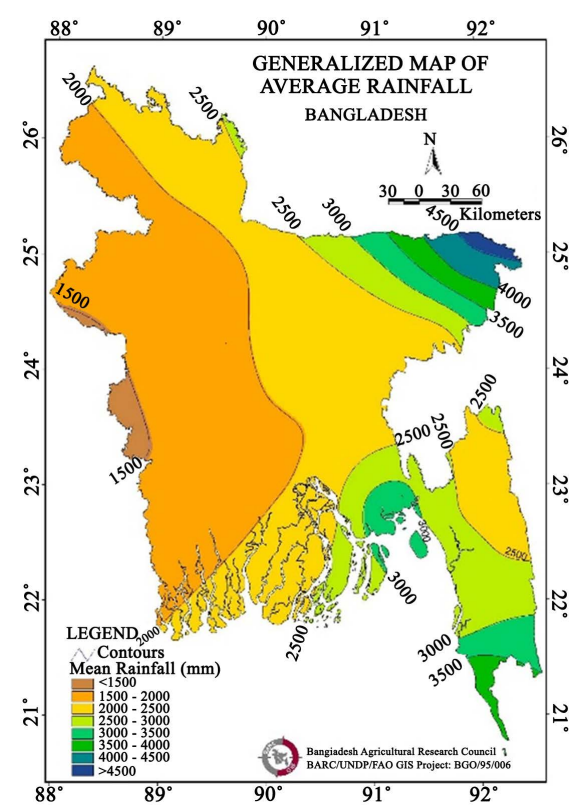

(a)

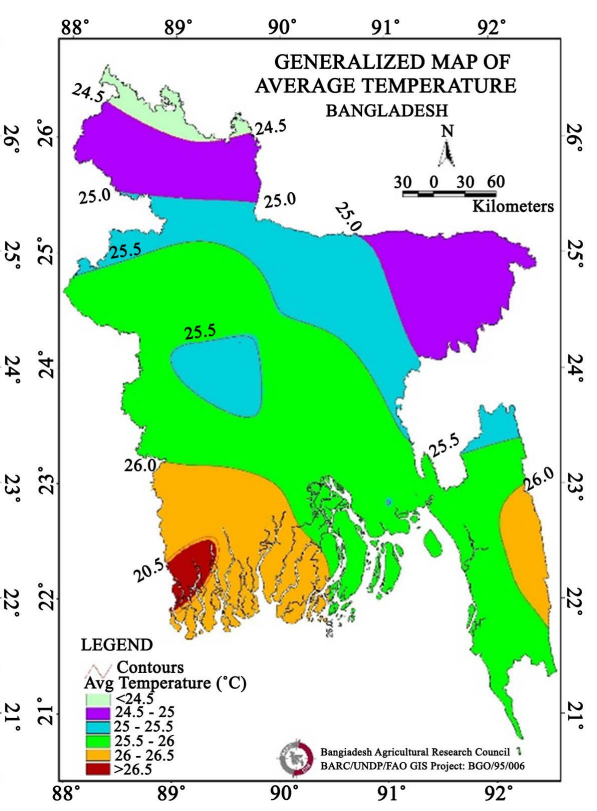

(b)

Figure 3. Generalized maps of (a) average rainfall in $\mathrm{mm}$ and (b) average temperature in ${ }^{\circ} \mathrm{C}$ in Bangladesh. 
As the season progresses, this discontinuity weakens and retreats toward the north-west and finally disappears by the end of the season, making room for the onset of the summer monsoon. The rainy season, which coincides with the summer monsoon, is characterized by the southerly or south-westerly winds, very high humidity, heavy precipitation, and long consecutive days of precipitation which are separated by short spells of dry days. Precipitation in this season is caused by the tropical depressions that enter the country from the BB.

\subsection{Daily Precipitation Trend}

Figure 4 shows daily precipitation trend from 1971 to 2014 for Sylhet station. The figure depicts 16,071 day's precipitation to show the variation of precipitation with their extremity. In 1974, 1987, 1998, 1999, 2004 and 2007, there were more precipitation compared to other years. In 1974, there was a devastating flood that caused $36 \%$ of the country inundated, damaged about 57.9 million US\$ and nearly 28,700 people died. In 1998, another hazardous flood caused $61 \%$ area of the whole country inundated, 45 million people affected, crop and other damage were about 1.2 billion US\$ and about 2300 people died. One more flood in 2007 resulted in inundation of $43 \%$ area of the whole country where 13.3 million persons were affected and 831 people died. Figure 4 illustrates a linkage between floods in the north-eastern Bangladesh and occurrences of excessive or extreme precipitation for those particular years. In 1974, 1987 and 2000 the daily extreme precipitation was 216, 302, and $362 \mathrm{~mm}$, respectively. Additionally, in 2004 another extreme precipitation spell was found from 5-12 July accounted for about $400 \mathrm{~mm}$ and ranked the highest precipitation all over Bangladesh.

Figure 5 shows the daily precipitation trend in Sreemangal (1971-2014) with extreme precipitations in 1974, 1976, 1977, 1993, 1988, 1990, 2000, 2001, 2002, and 2004. Due to extreme precipitation in 1974 and 1988, there occurred huge flooding in Bangladesh. The highest pick of precipitation was found in 1976 (514 mm), 1984 (313 mm), 1990 (296 mm) and 2009 (328 mm).

Figure 4 and Figure 5 show that the average value of precipitation in Sreemangal was lower than Sylhet, and in Sreemangal the precipitation was in slightly

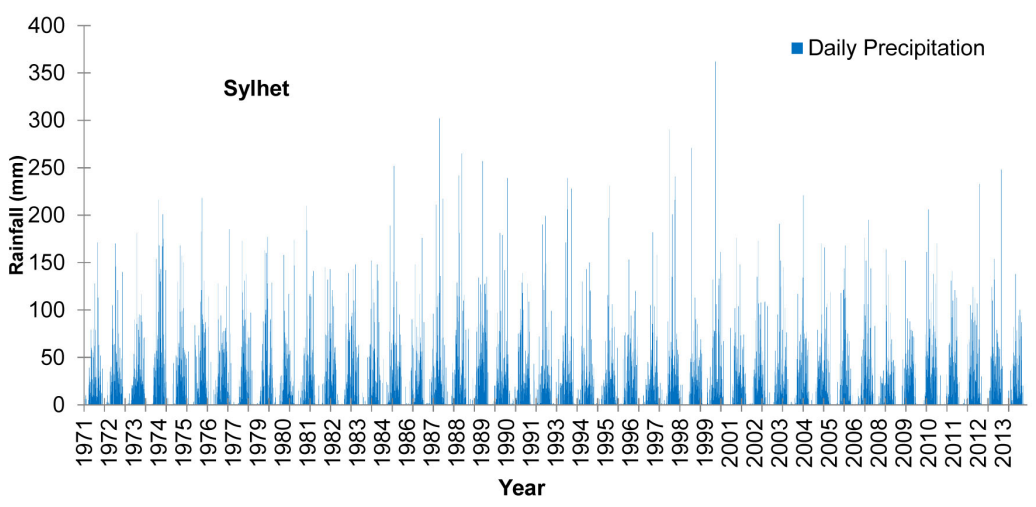

Figure 4. Daily precipitation trend (1971-2014) at Sylhet meteorological station. 


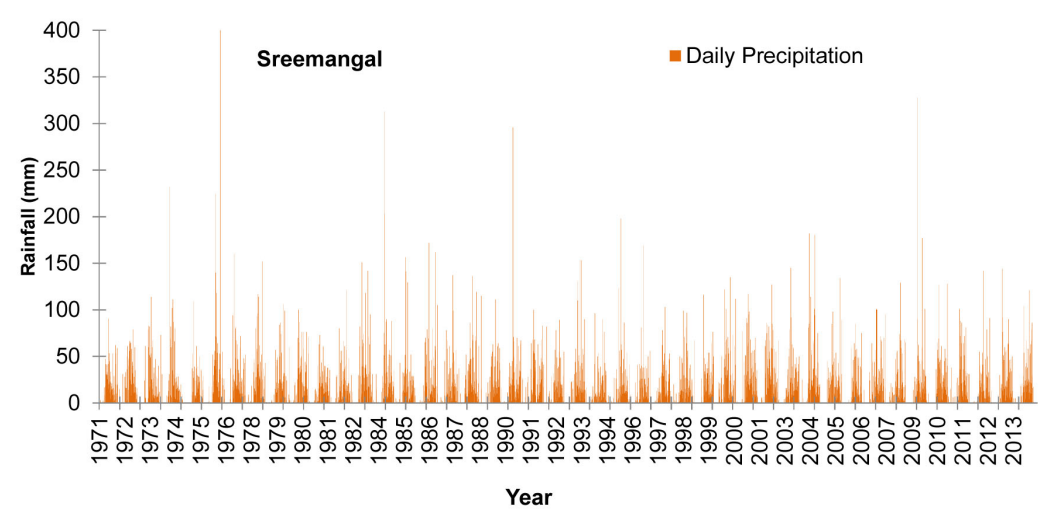

Figure 5. Daily precipitation trend (1971-2014) at Sreemangal meteorological station.

decreasing trend from 1971 to 2014. Rafiuddin et al. (2013) reported about the negative precipitation trend in Sreenamgal with maximum 173 days in 1953 and minimum 82 days in 1975.

\subsection{Extreme Precipitation in Sylhet and Sreemangal}

Figure 6 shows the long term extreme precipitation trend during tea growing season i.e., from April to September for Sylhet and Sreemangal from 1971 to 2014, where more than $\mathrm{N}^{\text {th }}$ percentile value (yearly $3396 \mathrm{~mm}$ for Sylhet and 1859 $\mathrm{mm}$ for Sreemangal) expressed as the extreme precipitation. Here, April to September were considered based on the acute plucking period of tea leaves and higher prevalence of extreme precipitation days.

The extreme precipitation days (i.e., days with $90^{\text {th }}$ percentile precipitation) from 1971 to 2014 reveals 132 days in April, 226 in May, 317 in June, 286 in July, 222 in August, and 208 days in September in Sylhet. The highest $90^{\text {th }}$ percentile days suggest June was the month with the maximum extreme precipitation days. In Sreemangal, April, May, July, August and September had gradually less days with extreme precipitation. June also had the highest $95^{\text {th }}$ and $99^{\text {th }}$ percentile precipitation days. The highest $90^{\text {th }}$ percentile day was 301 in May, 280 in June, and the lowest was 136 for April suggests that Sylhet had more extreme precipitation than Sreemangal.

Figure 7 shows the $90^{\text {th }}, 95^{\text {th }}, 99^{\text {th }}$ percentile days for Sylhet in the year of 1992 , 2000, and 2014. According to the BTB's Monthly Bulletin (February 2015) these 3 years were chosen based on higher tea production, and to find out the impacts of extreme precipitation on these production rates. In 1992, 2000 and 2014 the $90^{\text {th }}$ percentile days were the highest in June while the precipitation days gradually decreased in July, August and September. However, such amount of precipitation was helpful for the production of tea. In 1992, the $95^{\text {th }}$ percentile days were the highest in July, and in 2000 and 2014 the highest precipitation days were found in June. The maximum extreme precipitation days (i.e., the $99^{\text {th }}$ percentile days) were 8 in July of 1992, 11 in June of 2000, and 9 in May of 2014.

Figure 8 shows the $90^{\text {th }}, 95^{\text {th }}, 99^{\text {th }}$ percentile precipitation days from April to September in 1992, 2000, and 2014 for Sreemangal. In 1992 and 2000, the $90^{\text {th }}$ 


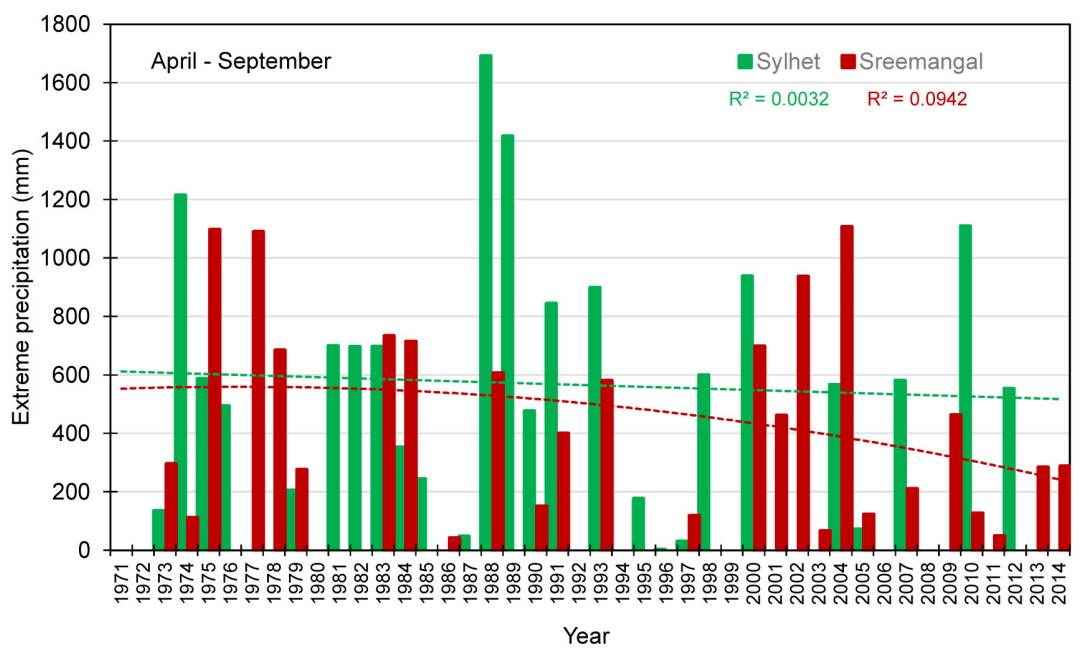

Figure 6. Extreme precipitation trend (1971-2014) at Sylhet and Sreemangal during tea growing season.

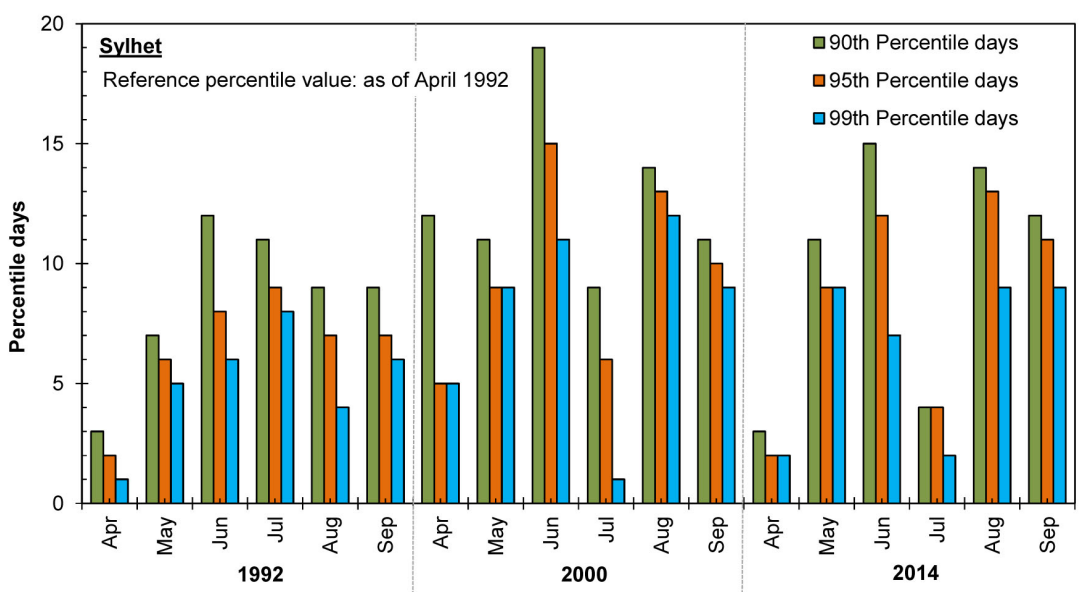

Figure 7. Calculated $90^{\text {th }}, 95^{\text {th }}$ and $99^{\text {th }}$ percentile precipitation days for tea growing season in 1992, 2000 and 2014 for Sylhet.

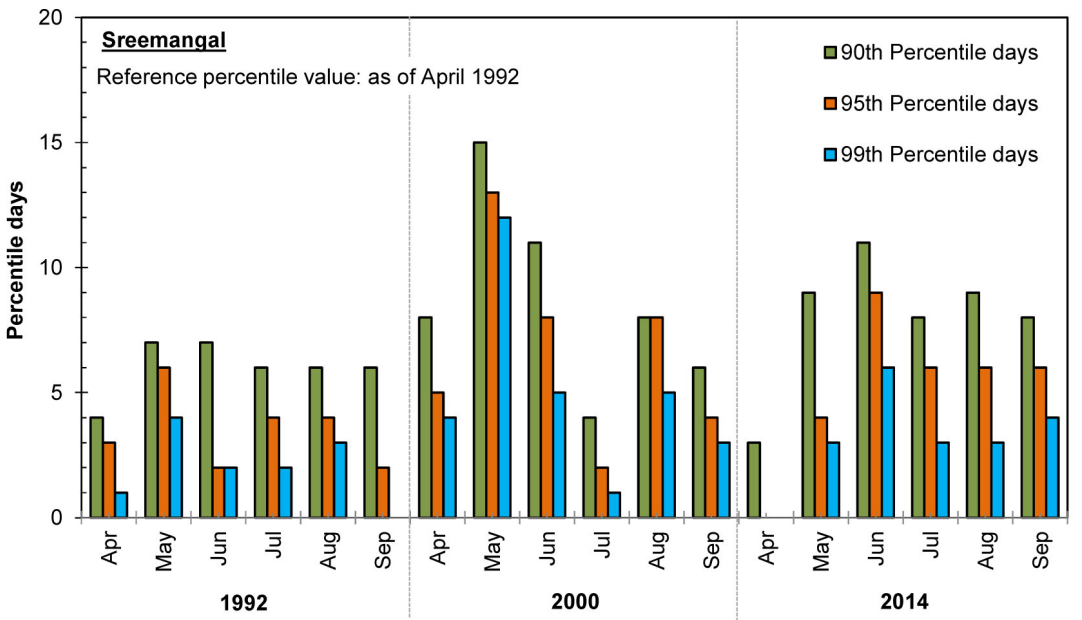

Figure 8. Calculated $90^{\text {th }}, 95^{\text {th }}$ and $99^{\text {th }}$ percentile precipitation days for tea growing season in 1992, 2000 and 2014 for Sreemangal. 
percentile days were the maximum in May and accounts for 7 and 12, respectively. In 2014, the maximum $90^{\text {th }}$ percentile days were in July (11) whereas, in 1992 the days slightly decreased. In 2000, the extreme precipitation days were fewer in July. April, June, August and September had moderate number of extreme precipitation days. In 2014, all the months showed higher number of extreme precipitation days than 2000 which suggests that the extreme precipitation was helpful for higher tea production in 2014.

\subsection{Tea Production in Bangladesh}

Bangladesh is the $10^{\text {th }}$ largest tea producer in the world and an important tea-exporting country also. Tea is the $2^{\text {nd }}$ largest export oriented cash crop of Bangladesh following jute. The country has 166 commercial tea estates including many of the world's largest working plantations. The industry accounts for $1 \%$ of national GDP and 3\% of global tea production employing more than 4 million people. The total cultivated area and total yearly production of tea is shown in Figure 9.

\subsection{Tea Production in Sylhet}

Among 20 tea estates of Sylhet (BTB, 2015) seven were selected within 2 kilometers of Sylhet meteorological station. Figure 10 shows the cultivation area and production at selected tea estates. In 1992, the total yearly precipitation was 3506 $\mathrm{mm}$ and $90^{\text {th }}, 95^{\text {th }}$, and $99^{\text {th }}$ percentile days were 51,39 and 30 , respectively. At Habibnagar tea estate higher amount of tea $(339 \mathrm{mKg})$ was produced inspite of lower cultivation area (229 ha). Lackatoorah, Star, Malnicherra and Alibaharestate produced relatively lower amount of tea. In 2000, the total yearly precipitation was $4692 \mathrm{~mm}$ while the $90^{\text {th }}, 95^{\text {th }}$, and $99^{\text {th }}$ percentile days were 76,58 and 47 recommends increase of extreme precipitation days at Sylhet station in 2000. The total yearly precipitation was $3372 \mathrm{~mm}$ in 2014 and the $90^{\text {th }}, 95^{\text {th }}$, and $99^{\text {th }}$ percentile precipitation days were 59, 51 and 38, respectively. Extreme precipitation days decreased in 2014 than 2000 at the same station.

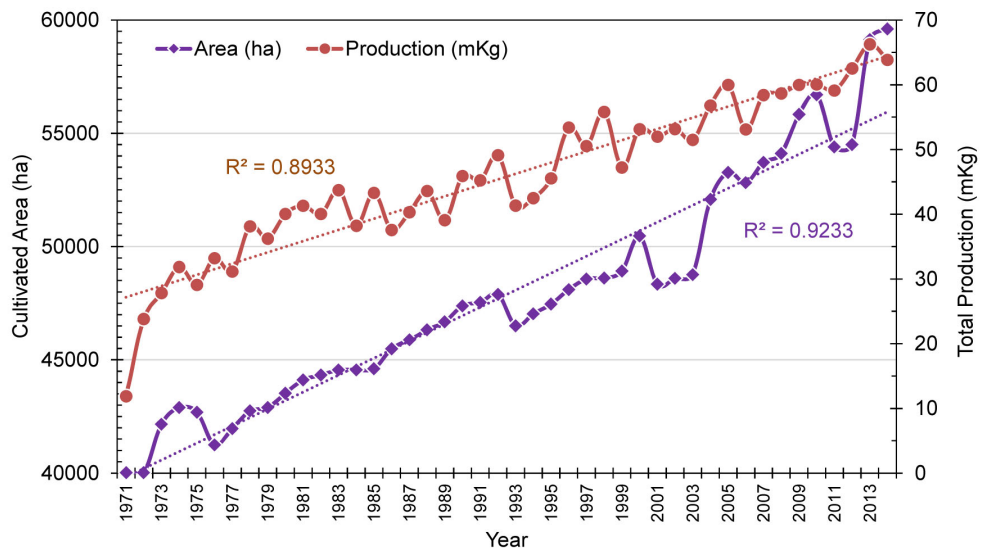

Figure 9. Cultivated area (in ha) and total tea production ( $\mathrm{mKg}$ ) in Bangladesh (1971-2014). 


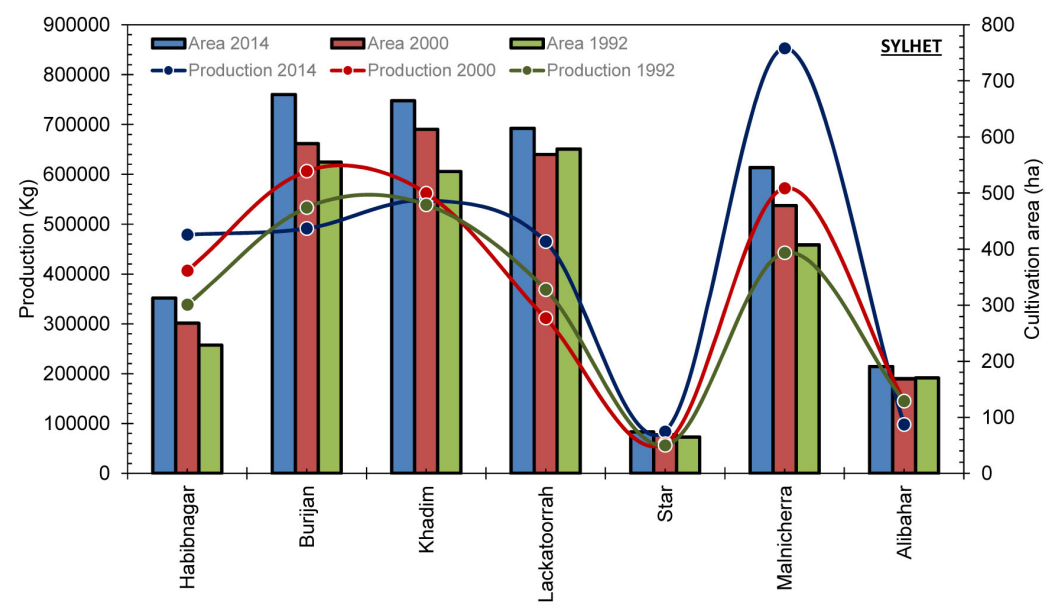

Figure 10. Tea production and cultivated area at selected tea estates in Sylhet.

\subsection{Tea Production in Sreemangal}

In Sreemangal, 9 estates were selected among 92 tea estates of Moulvibazar district. These estates are within 2 kilometers of the meteorological station of Sreemangal. Figure 11 shows production and cultivation area for these 9 tea estates. MR Khan, Julekhanagar, Hossainabad, Sathgaon estates show a good relation of tea production with the cultivation areas of the estates. Baraoora, Zareen and Junglebari show higher productivity compared with the cultivated areas. In Sreemangal, all the extreme precipitation days increased in 2000 than 1992 with the increase of tea production. On the other hand in Julekhanagar, Hossainabad and Sathgaon tea production relatively decreased compared to 1992 . The $90^{\text {th }}$ percentile days from May to September were $9,11,8,9$ and 8, respectively which helped higher tea production in 2014.

\subsection{Tea Production and Extreme Precipitation in the North-East}

Tea production is increasing day by day In Bangladesh. The year 1972, 1974, 1976, 1979, 1981, 1983, 1987, 1988, 1996, 1998, 2000, 2002, 2004, 2007, and 2012 had higher tea production where the total yearly precipitation was also higher than normal. For the mentioned years, the total precipitation and tea production increases consecutively from the previous years, and possess a good correlation in between these two parameters. Among the weather parameters of precipitation, temperature, humidity, evaporation and sunshine hour; perhaps precipitation plays the most important role in the development and growth of tea plants and ultimately yield per area (Ahmed et al., 2015). On the other hand, in 1975, 1984, 1986, 1989, 1997, 1999, 2001, 2006, 2008 and 2011, lower tea production was reported that resembles with lower precipitations in these years. Moreover, in 1994 and 2013 the opposite result was also observed where increasing precipitation decreased tea production. This exception may occur for the variation of soil fertility, temperature or continuous heavy precipitation. Figure 12 shows the contribution of extreme precipitation and tea production for the tea growing seasons. 


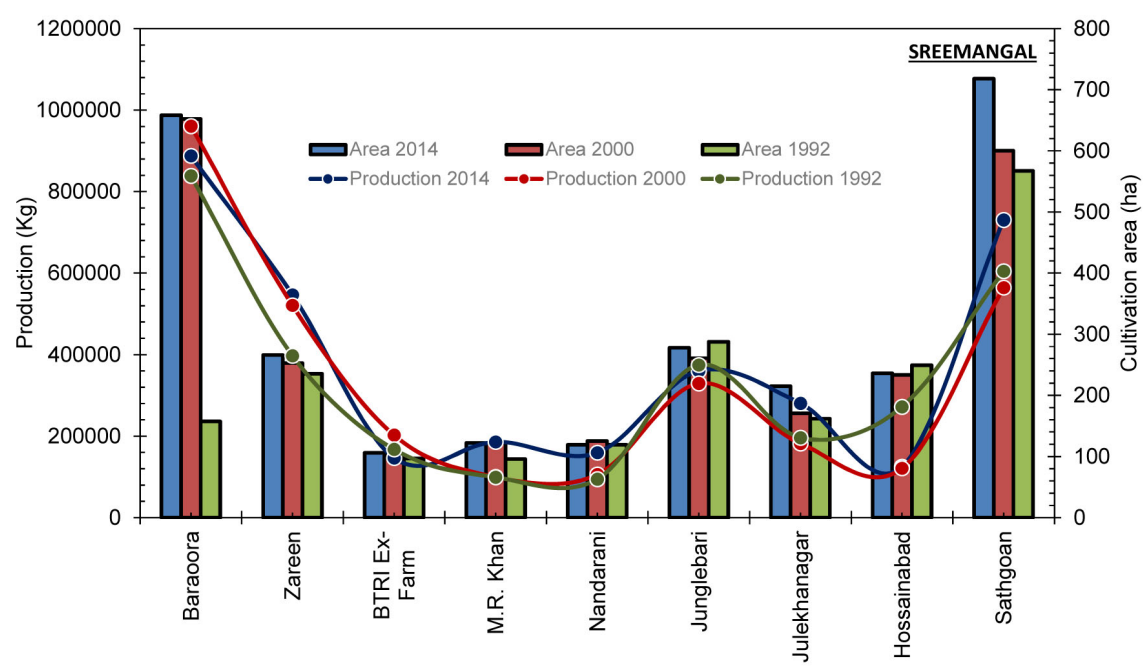

Figure 11. Tea production and cultivated area at selected tea estates in Sreemangal.

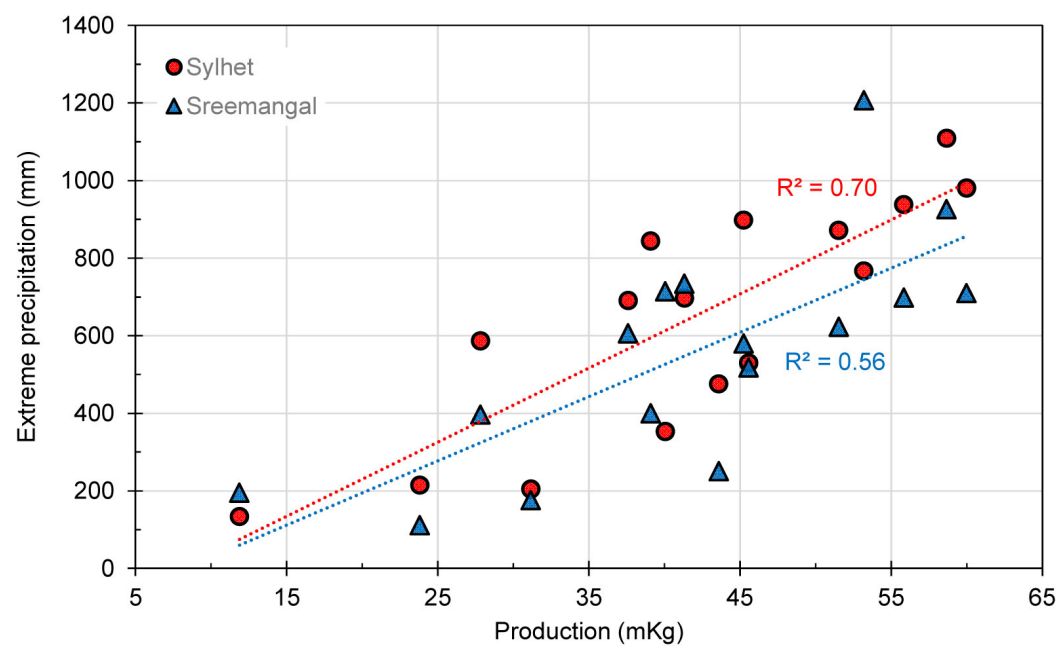

Figure 12. Contribution of extreme precipitation on tea production.

\section{Conclusion}

The study investigates the extreme $\left(90^{\text {th }}, 95^{\text {th }}\right.$ and $99^{\text {th }}$ percentile $)$ precipitation pattern in relation to tea production in Sylhet and Sreemangal. To analyze extreme precipitation, 44 years data (1971 to 2014) for Sylhet and Sreemangal meteorological station were taken into consideration. Variation of precipitation and extreme precipitation were significant for this study. In Sylhet, the precipitation level was higher in the year of 1974, 1983, 1988, 1989, 2004, 2007 and 2010. In 1974, 1987 and 2000, the daily extreme precipitation was 216, 302, $362 \mathrm{~mm}$, respectively. These extreme precipitations were responsible for flood but on the other hand produce high amount of tea. In Sreemangal, there were extreme precipitation in 1974, 1976, 1977, 1993, 1988, 1990, 2000, 2001, 2002, and 2004. The extreme precipitation in Sylhet showed the highest $90^{\text {th }}$ percentile days in June (317) and the lowest in April (132). In May, July, August and September the value was 220 . The $95^{\text {th }}$ and $99^{\text {th }}$ percentile precipitation days also followed the 
same rules. In Sreemangal, the $90^{\text {th }}$ percentile precipitation days were the highest in May (301) and on the following months decreased gradually. The result indicates that Sylhet possessed the maximum extreme precipitation days in June, and Sreemangal possessed in May. The results show that higher level of precipitation helps in production of higher amount of tea. The inter-relationship between extreme precipitation and tea production was strong for the selected areas.

\section{Conflicts of Interest}

The authors declare no conflicts of interest regarding the publication of this paper.

\section{References}

Ahammed, D. K. M. (2012). Investment for Sustainable Development of Bangladesh Tea Industry-An Empirical Study. Proceedings of BEA XVIII Biennial Conference, Paper No. 9, Bangladesh, September 2012, 12-16.

Ahmed, M., \& Mamun, M. S. A. (2012). Distributional Pattern and Seasonal Abundance of Major Pests of Tea in Bangladesh. Tea Journal of Bangladesh, 41, 1-10.

Ahmed, I., Hossain, A., Rowson, A., Haque, D. M. Z., Miah, M. L., \& Ahmed, T. (2015). Effect of Precipitation on Yield and Crop Distribution of Tea. Journal of Global Bioscience, 4, 2304-2314.

Ali, A. (1999). Climate Change Impacts and Adaptation Assessment in Bangladesh. Climate Research, 12, 109-116. https://doi.org/10.3354/cr012109

Ali, M., Uddin, M. N., Mobin, M. N., \& Saha, N. (2014). Effects of Microclimatic Parameter on Tea Leaf Production in Different Tea Estates, Bangladesh Journal of Environmental Science \& Natural Resources, 7, 183-188.

https://doi.org/10.3329/jesnr.v7i1.22168

Anon (1996). Tea from Sri Lanka (pp. 22-29). Colombo, Sri Lanka: Sri Lankan Tea Board.

Boehm, R., Cash, S. B., Anderson, B. T., Ahmed, S., Griffin, T. S., Robbat, A., Stepp, J. R., Han, W. Y., Hazel, M., \& Orians, C. M. (2016). Association between Empirically Estimated Monsoon Dynamics and other Weather Factors and Historical Tea Yields in China: Results from a Yield Response Model. Climate, 4, 20-27.

https://doi.org/10.3390/cli4020020

BTB (Bangladesh Tea Board) (2015). Statistical Report of Tea in Bangladesh (pp. 1-149). Sreemangal: Bangladesh Tea Board.

Carr, M. K. V., \& Stephens, W. (1992). Climate Weather and the Yield of Tea. In K. C. Willson, \& M. N. Clifford (Eds.), Tea: Cultivation to Consumption (pp. 87-135). London: Chapman and Hall. https://doi.org/10.1007/978-94-011-2326-6_4

Cottam, H. (1997). Tea Cultivation in Assam (pp. 103-107). Colombo.

Duncan, J. M. A., Saikia, S. D., Gupta, N., \& Biggs, E. M. (2016). Observing Climate Impacts on Tea Yield in Assam, India. Applied Geography, 77, 64-71.

https://doi.org/10.1016/j.apgeog.2016.10.004

Esham, M., \& Garforth, C. (2013). Climate Change and Agricultural Adaptation in Sri Lanka: A Review. Climate and Development, 5, 66-76.

https://doi.org/10.1080/17565529.2012.762333

Hamjah, R. (2014). Climatic Effects on Cotton and Tea Production. Tea Journal Bangladesh, 43, 10-19. 
Hicks, A. (2001). Review of Global Tea Production and the Impact on Industry of the Asian Economic Situation. In Asian Int. Tea Conf. 98 (Vol. 5, pp. 227-231), Singapore.

Huq, S., Karim, Z., Asaduzzaman, M., \& Mahtab, F. (1998). Vulnerability and Adaptation to Climate Change for Bangladesh. Dordrecht: Kluwer Academic Publishers. https://doi.org/10.1007/978-94-015-9325-0

Khan, A. Q., Biswas, A., Saha, A. K., \& Motalib, M. A. (2012). Soil Properties of Lalmai Hill, Shalban Bihar and Nilachal Hill of Greater Comilla District and Its Suitability for Tea Plantation. Tea Journal Bangladesh, 41, 17-26.

Mamun, M. S. A. (2011). Development of Tea Science and Tea Industry in Bangladesh and Advances of Plant Extracts in Tea Pest Management. International Journal of Sustainable Agriculture \& Technology, 7, 40-46.

Ochieng, J., Kirimi, L., \& Mathnge, M. (2016). Effects of Climate Variability and Change on Agriculture Production: The Case of Small Scale Farming in Kenya. NJAS-Wageningen Journal of Life Sciences, 77, 71-78. https://doi.org/10.1016/j.njas.2016.03.005

Paul, S. K., Ahmed, M., \& Mamun, M. S. A. (2014). Biopesticides: a Potential Tool for the Management of Plant Parasitic Nematodes in Tea. Tea Journal Bangladesh, 43, 24-33.

Rafiuddin, M., Uyeda, H., \& Islam, M. N. (2013). Simulation of Characteristics of Precipitation Systems Developed in Bangladesh during Pre-Monsoon and Monsoon. Proceedings of the 2nd International Conference on Water and Flood Management Held at Dhaka, Bangladesh, March 2009 (Vol. 1, pp. 61-68), Dhaka: Institute of Water and Flood Management, BUET, Publication.

Rahman, M. M., Kalam, M. A., \& Islam, M. M. (2012). Change of Chemical Compositions in Semi-Fermented Tea on Land Elevation. Tea Journal Bangladesh, 41, 11-16.

Rana, M., Shafee, S., \& Karmakar, S. (2007). Estimation of Precipitation in Bangladesh by using Southern Oscillation Index. Pakistan Journal of Meteorology, 4, 7-23.

Wijeratne, M. A., Anandacoomaraswamy, A., Amarathunga, M. K. S. L. D., Ratnasiri, J., Basnayake, B. R. S. B., \& Kalra, N. (2007). Assessment of Impact of Climate Change on Productivity of Tea (Camellia sinensis L.) Plantations in Sri Lanka. Journal of the National Science Foundation of Sri Lanka, 35, 119-126.

https://doi.org/10.4038/jnsfsr.v35i2.3676 